\title{
Modification of Primary Avalvular Varicose Anomaly after endovenous radiofrequency ablation
}

\author{
Primary Avalvular Varicose Anomalies before and after RFA \\ Veränderungen von Primary Avalvular Varicose Anomalies nach
endovenöser Radiofrequenzablation.
}

Authors

Daniele Bissacco, Silvia Stegher, Fabio Massimo Calliari, Marco Piercarlo Viani

Affiliations

ASST Fatebenefratelli-Sacco, Vascular Surgery Unit, Milan, Italy

Key words

Varicose veins, radiofrequency ablation, duplex ultrasound, PAVA.

Schlüsselwörter

Varikose, Radiofrequenzablation, Sonographie, PAVA

received $\quad 30.07 .2018$

accepted 21.02.2019

Bibliography

DOI https://doi.org/10.1055/a-0861-7830

Online-Publikation: 10.04.2019

Phlebologie 2019; 48: 373-376

(c) Georg Thieme Verlag KG Stuttgart · New York

ISSN 0939-978X

Correspondence

Dr. med. Daniele Bissacco

ASST Fatebenefratelli-Sacco, Vascular Surgery Unit

p.zza Principessa Clotilde 3

20121 Milan, Italy

Phone: + 390263632400

Mail: danielebissaccomd@gmail.com

\section{ABSTRACT}

Primary avalvular varicose anomaly (PAVA) is a new medical concept defined as primary varicose veins resembling neovascularized tissue on ultrasound examination. PAVAs could be misdiagnosed as recurrence at the saphenofemoral or saphenopopliteal junction, but no studies have yet examined their role before and after venous invasive procedure. In this report, we describe a case of PAVA in a 39-year-old man with symptomatic varicose veins and great saphenous vein truncal incompetence. Six months after radiofrequency ablation of the great saphenous vein, duplex ultrasound revealed complete occlusion of great saphenous vein and partial thrombosis of the still incompetent PAVA.

\section{ZUSAMMENFASSUNG}

Primär avalvuläre variköse Anomalien (PAVA) sind ein neues medizinisches Konzept, definiert als primäre Varikosis, die duplexsonographisch dem neuvaskularisierten Gewebe ähnelt. PAVA können mit Rezidiven im Bereich der Crosse assoziiert sein; keine Studie hat jedoch ihre Rolle vor und nach dem invasiven Eingriff untersucht.

In diesem Report beschreiben wir ein Fall von PAVA in einem 39-jährigen Patienten mit symptomatischen Varizen und Saphena magna-Stamminkompetenz. Sechs Monate nach Radiofrequenzablation der Vena Saphena Magna zeigte die Duplexsonographie einen kompletten Verschluss der Vena Saphena Magna und eine partielle Thrombose der weiterhin inkompetenten PAVA.

\section{Introduction}

Primary avalvular varicose anomaly (PAVA) is a new phenomenon defined as tortuous, thin-walled and incompetent veins in patients presenting with primary varicose veins (VVs), resembling neovascularized tissue on ultrasound and surgical examination [1].

The concept of PAVA was introduced to justified saphenofemoral junction (SFJ) recurrence with an aspect of neovascularization, after endovenous or surgical saphenous intervention. In particular, the misdiagnosis of a PAVA - already present before surgery - mistak- en for neovascularized tissue in recurrent VVs, may lead to underestimating the role of these avalvular residual SFJ collaterals after ablative intervention as a source of recurrence. The recognition of SFJ collaterals' incompetence has a greater relevance in case of endovenous procedure, in which only saphenous axis is treated. We present a case of PAVA, originating from SFJ, in a patient who underwent radiofrequency ablation (RFA) for incompetent great saphenous vein (GSV) and describe Doppler ultrasound scan (CDUS) PAVA modifications during follow-up period. 

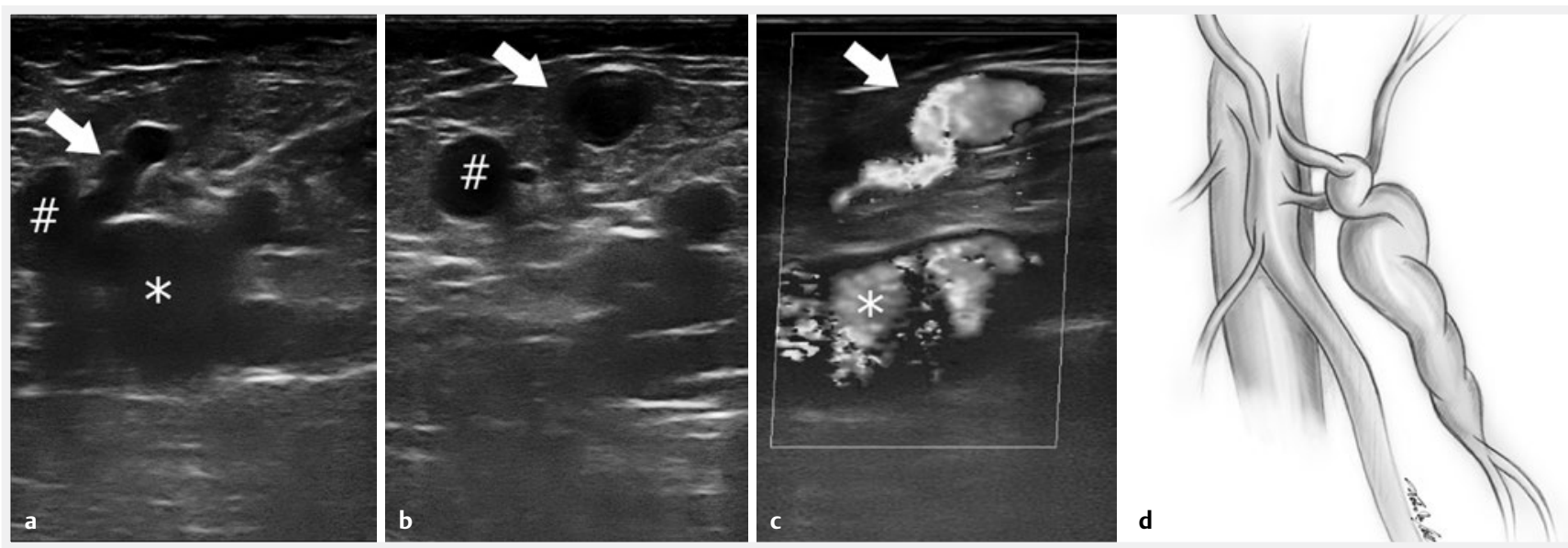

-Fig. 1 Preoperative CDUS analysis of saphenofemoral junction with femoral vein (asterisk), great saphenous vein (hashtag) and PAVA (arrow), proximal cross section, A and B. Longitudinal section of incompetent PAVA, C. Graphic overview of preoperative saphenofemoral junction with its collaterals, great saphenous vein and PAVA, D.

The patient provided written consent for the publication of this paper in a medical journal.

\section{Case report}

A 39-year-old man presented to our attention with primary varicose veins (C2-S; Ep; As; Pr2,5). He has a past medical history of appendectomy and adenoidectomy during his youth, prior episode of prostatitis and occasional asthma treated with bronchodilator medication (Salmeterol and Fluticasone) when needed. He also reported a familiar asymptomatic Fahr's syndrome, genetically diagnosed with mutation in SLC20A2 gene, with no basal ganglia or electrolyte homeostasis involvement, as demonstrated by head computed tomography scan and blood test performed one month before the procedure. Intolerance to acetylsalicylic-acid was reported.

A preoperative CDUS analysis revealed SFJ reflux with incompetence of both terminal and preterminal valves during Valsalva maneuver. A pathological reflux $>0.5$ s extending along the course of GSV, up to the knee, was detected. Extra-saphenous varicose vein along the leg were also present. GSV diameter was measured at proximal, middle and distal thigh, being $8.7 \mathrm{~mm}, 10.7 \mathrm{~mm}$ and $9.5 \mathrm{~mm}$, respectively. GSV-skin distances were also measured at same thigh levels: $17 \mathrm{~mm}, 19 \mathrm{~mm}$ and $8 \mathrm{~mm}$, respectively. Neither thigh GSV incompetent collaterals nor anterior accessory saphenous vein (AASV) were detected.

During the CDUS exam, a SFJ collateral, next to the connection with femoral vein, was noted ( $\triangleright$ Fig. 1 ). It was a serpiginous, avalvular, dilated, refluxing collateral, extending from SFJ to saphenous space, wrapping the GSV in its proximal tract. Its maximum diameter was $9.9 \mathrm{~mm}$ proximal to the SFJ. Distally at middle third level of the thigh, the collateral became suprafascial, with a marked decrease in caliber and the abolition of reflux. It was not possible to describe neither where this collateral originated from nor which district it drained. The patient underwent endovenous ablation of GSV using radiofrequency with ClosureFAST ${ }^{\mathrm{TM}}$ catheter (Medtronic, San Jose, CA, USA) and concomitant phlebectomies of the leg under local anesthesia ( $\triangleright$ Fig. 2). Neither intraprocedural nor postprocedural complications occurred. Patient was discharge the same day of the procedure with compression stockings $(20-30 \mathrm{mmHg})$ for two weeks and prophylactic dose of low molecular weight heparin for twelve days.

After six months, the patient underwent CDUS control examination that revealed good results of endovenous ablation, with patency of SFJ through the superficial epigastric vein. The tortuous SFJ collateral was still patent, with maximum diameter of $7.8 \mathrm{~mm}$ and partial circumferential thrombosis of the distal portion, with a residual lumen of $4.8 \mathrm{~mm}$ in diameter ( $>$ Fig. 3). Residual reflux was detected in this tributary vein during Valsalva maneuver. No clinical signs of residual or recurrent VVs was present. Reviewing pre-interventional CDUS images and comparing them with the follow-up images, a truncal PAVA was then diagnosed.

\section{Discussion}

Varicose veins recurrence remains one of the most undisclosed and debated topic in phlebology with a wide incidence range from $7 \%$ to $65 \%$ [2]. Moreover, the pathogenesis of recurrent SF] reflux remains incompletely understood, even if several studies have proposed different pathological causes [3-7]. Among these, neovascularization has been reported to account from $8 \%$ to $60 \%$ of recurrent VVs $[2,8,9]$. Tactical and technical errors were detected in $80 \%$ of cases, although incidences remain very heterogeneous among studies $[2,10,11]$ with unclear correlation between recurrent VVs defined with CDUS, surgical or histological examination [12].

PAVA is a new anatomical entity consisting of serpiginous, avalvular and usually incompetent veins arising from SFJ or directly from femoral vein, detected during preoperative CDUS evaluation [1]. Three patters of PAVA were described by Ostler and collaborators [1]:

- Lymph node pattern: PAVA emerge directly from a groin lymph nodes

- Peritruncal pattern: PAVA wrap around truncal veins (the GSV, small saphenous vein, or anterior accessory saphenous vein) 


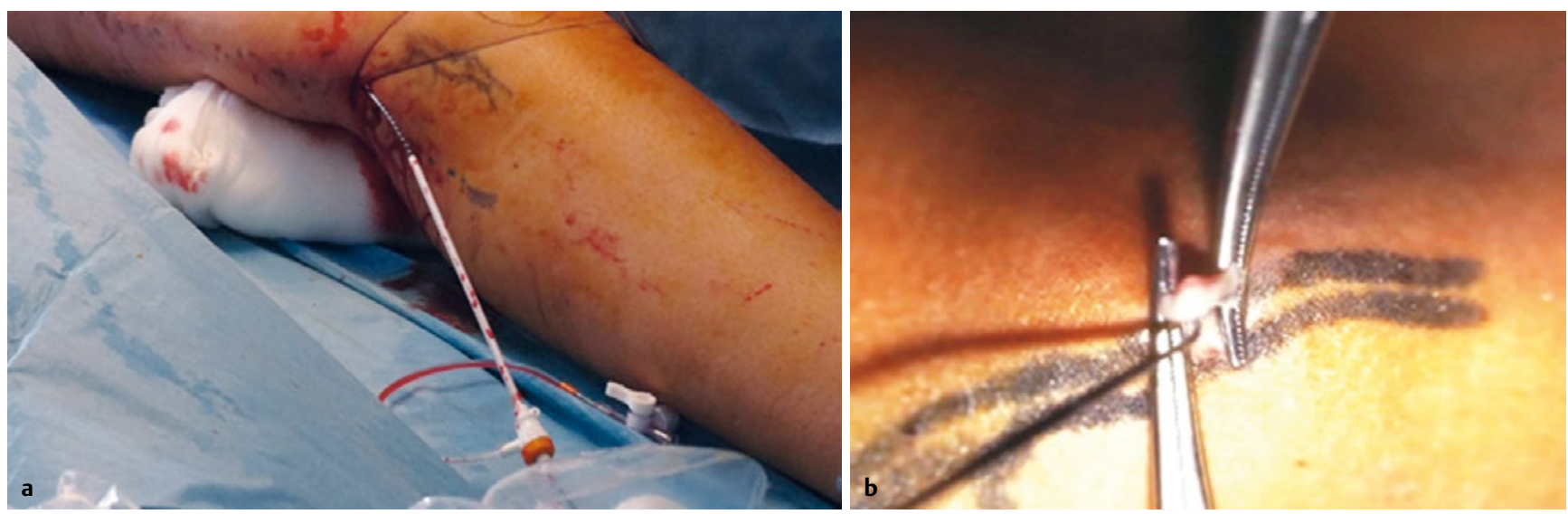

- Fig. 2 Endovenous ablation of GSV was performed using radiofrequency ablation technique with ClosureFAST ${ }^{\mathrm{TM}}$ catheter (Medtronic, San Jose, CA, USA), A. Concomitant phlebectomies of the leg under local anesthesia were also performed, $B$
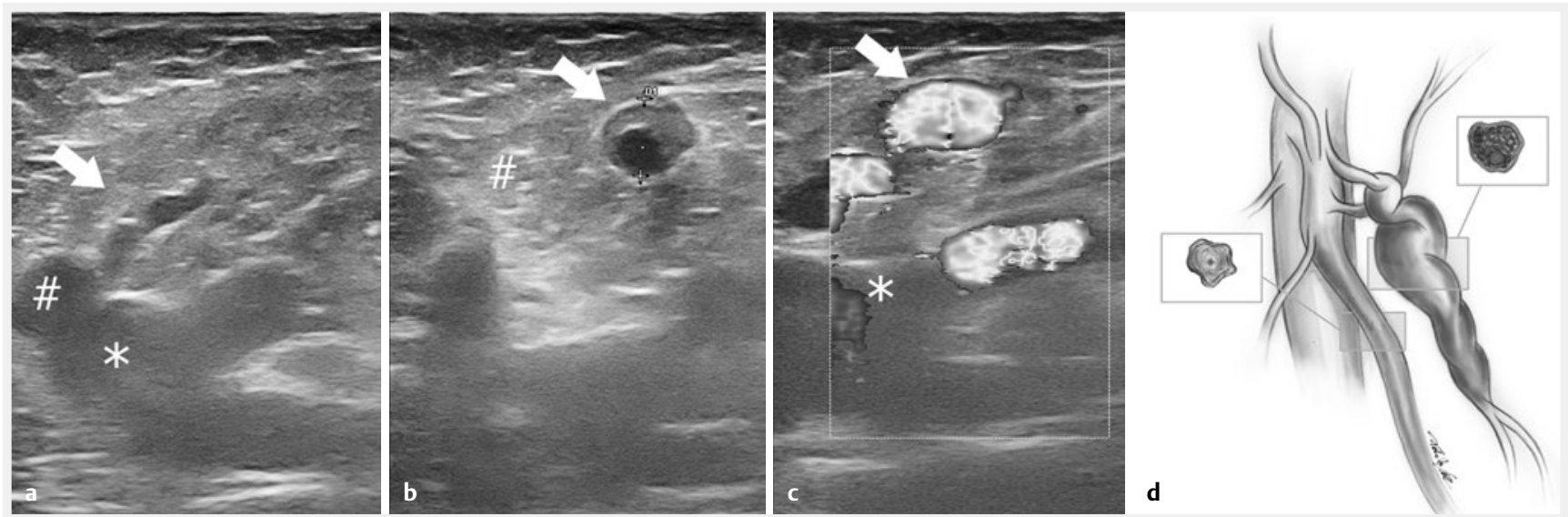

-Fig. 3 Post-RFA six-month CDUS analysis, revealing patency of femoral vein (asterisk), saphenofemoral junction, proximal great saphenous vein (hashtag) and proximal PAVA (arrow), A. Total occlusion of great saphenous vein due to RFA (hashtag), with partial PAVA occlusion (arrow), still incompetent, B and C. Graphic overview of postoperative saphenofemoral junction with its collaterals, great saphenous vein, PAVA and their cross sectional lumen view, D.

- Atypical pattern: PAVA have the same appearance as the other two patterns but lie in various locations and are not connected to lymph nodes or truncal veins.

The incidence of PAVA is around $5 \%$ among CDUS examinations, with a female-to-male ratio of about 5:1 and with no significant correlation with CEAP grade [1].

The recognition of PAVA during CDUS examination is challenging because it may be confused with SFJ collateral or with GSV groin tributaries with poor or none clinical significance. The differences have not yet been clearly defined. PAVA differs from AASV for the absence of valves and the serpiginous course, not parallel to GSV.

We report a case of a patient with truncal PAVA undergoing to a RFA procedure.

PAVA was not treated because it was recognized only during retrospective imaging.

At 6-month CDUS follow-up, a good clinical and instrumental result were evident, although PAVA was still incompetent, with distal partial circumferential vein lumen thrombosis (residual lumen of $4.8 \mathrm{~mm}$ ) and a decrease in maximum diameter (from $9.9 \mathrm{~mm}$ to
$7.8 \mathrm{~mm}$ ). The reasons for these two changes remains unknown. Furthermore, we do not know if in future this collateral could become a source of recurrent VVs, but we would like to introduce the hypothesis that some recurrent VVs cases considered as neovascularization, could be a residual PAVA. The misdiagnosis derives from similarity in recurrent VVs and PAVA appearance (avalvular, shaped, next to SFJ, ...). The fact that, 6 month after endovenous procedure, PAVA is still incompetent may justify its role as a future source of reflux in the SFJ thus creating recurrent VVs.

For these reasons, it should be recommended to detect PAVA during preoperative CDUS examination and during follow up controls, in order to clarify:

- if PAVA is primarily observed as a patent and competent/incompetent vessel, and remains or become incompetent after RFA or others venous treatment

- if PAVA modifies its diameter after intervention, producing new varices or dilated veins

- if PAVA represents a potential new source of pathological/ symptomatic reflux 


\section{- if it is necessary to remove PAVA in case of surgery or sclero-} therapy for recurrent VVs.

The answers to these questions might strongly modify CDUS approach and change management and treatment of primary and recurrent VVs.

\section{CONCLUSION}

Primary Avalvular Vein Anomalies are not so rare in patients performing a CDUS analysis for varicose veins. It is important to detect PAVA during preoperative examination and report its presence in order to correlate it to a possible recurrence of VVs. The need for new studies that could identify a correlation between recurrent $\mathrm{VVs}$ patters and preoperative PAVA is necessary to confirm the role of these veins in the recurrence of symptomatic chronic venous disease.

\section{Conflict of Interest}

The authors declare no conflict of interest.

\section{Acknowledgment}

We would like to thank $\mathrm{Dr}$ med Tersalvi $\mathrm{G}$ for german translation and revision.

\section{References}

[1] Ostler AE, Holdstock JM, Harrison CC et al. Primary avalvular varicose anomalies are a naturally occurring phenomenon that might be misdiagnosed as neovascular tissue in recurrent varicose veins. J Vasc Surg Venous Lymphat Disord 2014; 2(4): 390-396

[2] Brake M, Lim CS, Sheperd AC et al. Pathogenesis and etiology of recurrent varicose veins. J Vas Surg 2013; 57(3): 860-868

[3] Perin MR, Labropoulos N, Leon LR. Presentation of the patient with recurrent varices after surgery (REVAS). J Vasc Surg 2006; 43(2): 327-334

[4] De Maeseneer MG, Vanderbreeck CP, Lauwers PR et al. Early and late complications of silicone patch sapohenoplasty at the saphenofemoral junction. J Vasc Surg 2006; 44: 1285-1290

[5] De Maeseneer MG, Philipsen TE, Vanderbreeck CP et al. Closure of cribriform fascia: an efficient anatomical barrier against post-operative neovascularization at the saphenofemoral junction? A prospective study. Eur J Vasc Endovasc Surg 2007: 34: 361-366

[6] Frings N, Nelle A, Tran PH et al. Reduction of neoreflux after correctely performed ligation of the saphenofemoral junction. A randomized trial. Eur J Vasc Endovasc Surg 2004: 28: 246-252

[7] Winterborn RJ, Earnshaw JJ. Randomized trial of Plytetrafluooethylene patch insertion for recurrent greta saphenous varicose veins. Eur J Vasc Endovasc Surg 2007; 34: 367-373

[8] Kostas T, loannou CV, Touloupakis E et al. Recurrent varicose veins after surgery: a new appraisal of a common and complex problem in vascular surgery. Eur J Vasc Endovasc Surg 2004; 27: 275-282

[9] Egan B, Donnelly M, Bresnihan M et al. Neovascularization: an "innocent bystander" in recurrent varicose veins. J Vasc Surg 2006; 44: 1279-1284

[10] Stonebridge PA, Chalmers N, Beggs I et al. Recurrent varicose veins: a varicographic analysis leading to a new practical classification. $\mathrm{Br}$ ] Surg 1995; 82: 60-62

[11] Allegra C, Antignani PL, Carlizza A. Recurrent varicose veins following surgical treatment: our experience with five years follow-up. Eur J Vasc Endovasc Surg 2007; 33: 751-756

[12] Viani MP, Nano G, Stegher S et al. Recurrent varicose veins. Histopathological evaluation and new perspective: preliminary results. It ] Vasc Endovasc Surg 2010; 17(suppl 1): 277-283 